\title{
Adverse Selection and the Choice between Joint Ventures and Acquisitions: Evidence from Spanish Firms
}

\author{
by \\ Cristina López-Duarte ANd Esteban García-CANAL*
}

\begin{abstract}
We analyze the determinants of the choice between greenfield joint ventures, full acquisitions, and partial acquisitions in the internationalization expansion of a firm through foreign direct investments. Our results show that this choice is conditioned by transaction-cost factors (particularly the cultural distance between the home and host countries), as well as by the previous experience and internationalization path of the foreign investor, as suggested by the knowledge-based theories of the firm. (JEL: F 21, F 23, L 14)
\end{abstract}

\section{Introduction}

Joint ventures (JVs) and acquisitions have traditionally been analyzed as alternative means of gaining access to assets whose transfer in the market involves high transaction costs (TCs) (BALAKRISHNAN AND KoZA [1993], CHI [1994], HENNART AND REDDY [1997]). Intangible assets and the specific know-how of firms are among such assets (HENNART [1988]). JVs and acquisitions are likewise seen in the literature on foreign market entry as alternative means of gaining access to firm-specific knowledge related to a foreign market ${ }^{1}$ (KogUT AND SINGH [1988]; HENNART AND REDDY [1997], [2000]; REUER AND KoZA [2000]). This is the asset a company most commonly lacks when investing abroad.

Although both JVs and acquisitions allow the foreign investor to gain access to the resources it lacks, they do so in very different ways. While JVs allow the foreign investor to combine its firm-specific competences with those of the other partners, acquisitions imply buying the whole package of assets of the local firm. Previous research has highlighted two important problems arising in acquisitions that can lead

\footnotetext{
* We thank two anonymous referees and the editor Elmar Wolfstetter for their guidance through the evaluation of this paper. We also thank Geert Hofstede for providing us with updated information to calculate cultural distance. Financial support from Spain's Ministerio de Ciencia y Tecnología (Project SEC 2000-0587) is gratefully acknowledged.

${ }^{1}$ Like, for instance, the knowledge related to the structure of distribution networks or the specific needs of the local customers.
} 
firms to prefer JVs. On the one hand, BALAKRISHNAN AND KOZA [1993] analyzed the adverse-selection problems that can arise when acquiring other firms under information asymmetry. KoGUT AND SINGH [1988] and HENNART AND REDDY [1997], on the other hand, focused their attention on the integration and digestibility problems that can appear when acquiring culturally distant or large and nondiversified partners. In a recent paper, REUER AND KOZA [2000] argue that these two perspectives are complementary rather than competitive, as "the ex ante valuation uncertainties highlighted by the asymmetric information view are apt to exist when ex post integration challenges noted by the indigestibility perspective are present." In particular, they claim that when acquiring a firm embedded in a different culture, the acquiring firm faces both an adverse-selection problem and an integration problem after the acquisition. Cultural distance is thus a key factor influencing ex ante and ex post costs related to international acquisitions.

With the aim of clarifying to what extent these two perspectives are complementary, we examine the choice between JVs and acquisitions, taking into consideration two issues related to this choice that remain unexplored in the literature on foreign market entry. Firstly, this process is usually analyzed as the choice between the setting up of a greenfield JV in the host market and the full acquisition (FA) of a firm located in this market. There is, however, a hybrid option between these two alternatives, namely partial acquisitions (PAs). For the purposes of this study, PAs are understood as acquisitions (by just one firm or by several firms) of a part of the equity of a firm previously located in the host market. PAs thus combine some characteristics of both FAs and JVs. On the one hand, like FAs they imply acquiring equity of an existing firm; on the other hand, like JVs they imply sharing the control of the foreign unit with other partners. Even though some researchers have pointed out the need to compare full and partial acquisitions when investing abroad (HENNART AND REDDY [2000, p. 193]), PAs have rarely been taken into account in the literature on foreign market entry. Only BARKEMA AND VERMEULEN's [1998] study took this alternative option into consideration when analyzing the influence of multinational diversity, product diversity, and product relatedness on the choice of entry mode. However, cultural distance was used as a control variable in that study, and so a theoretical framework analyzing its influence on the choice of entry mode was not developed.

A second issue that has rarely been explored in this field is that related to the dynamic aspects of the internationalization process through foreign direct investment (FDI). Employing a TC theoretical framework, HENNART [1991] and HENNART AND LARIMO [1998] analyzed how the experience gained by the firm in one country influenced the ownership structure of further foreign subsidiaries in that country. However, the effect of the experience gained in the use of different entry modes or in the internationalization process has still to be analyzed when studying the choice between JVs and acquisitions. We think this is a particularly important factor, insofar as the experience accrued by the firm when investing abroad through acquisitions may soften the aforementioned ex ante and ex post costs related to acquisitions in large-cultural-distance contexts. 
Taking into account that there exists a hybrid option between JVs and acquisitions, we analyze the effect of national culture and accrued experience on the choice of entry mode. Within this context, we consider PAs as an independent option to gain access to external firm-specific resources and analyze how adverse-selection problems or integration costs affect the choice of this entry mode. In order to analyze asset and knowledge integration problems, we go beyond propositions based on internalization/transaction-cost theory (TCT) (BUCKLEY AND CASSON [1976]; TEECE [1976], [1977]; HENNART [1982]), using insights from the knowledge-based theories of the firm (KBTFs) (Kogut And ZANDER [1993], MADHOK [1997]). Although they lead to the same predictions of the choice between JVs and FAs, we argue in this paper that they lead to contrary predictions when we consider PAs as an entry mode. We test our predictions using a sample of productive foreign investments made by Spanish firms. The use of data relative to Spanish firms is another distinctive feature of this paper, as other studies have used data from American or Japanese firms, which have a higher degree of international involvement than Spanish ones. ${ }^{2}$ Our sample allows us to analyze the effect of cultural distance insofar as the FDIs collected in the database were made by Spanish firms in very different countries.

The paper is organized as follows: First, we briefly summarize the TC and knowledge-based views of the firm and the findings of previous research. Next, we analyze the effect of national cultural distance on entry mode from the TCT and KBTF perspectives. We then analyze the effect of previous experience on entry modes, and the empirical propositions derived from each approach are tested using the aforementioned sample of FDIs. After discussing our empirical results, the main conclusions reached are presented.

\section{Summary of Previous Research}

TC and internalization theories are primarily concerned with opportunistic behavior and uncertainty. According to these theories, multinational enterprises (MNEs) arise in order to economize on the TCs associated with the markets for international transfer of technology and knowledge. Firms expand their boundaries in order to exploit abroad certain firm-specific assets - most usually, intangible assets - developed in their home market (BUCKLEY AND CASSON [1976]; TEECE [1976], [1977]; HENNART [1982]). The possession of such assets leads to FDI, as their transfer through the market involves high TCs due to the opportunism hazards associated with knowledge diffusion (ARROW [1962]) and small-numbers bargaining (WILLIAMSON [1975]). In order to avoid these TCs, the natural way of expanding through direct investment is the establishment of a wholly owned subsidiary (WOS):

2 An important feature of Spanish FDI is its late liberalization, which was not consolidated until Spain entered the European Economic Community - nowadays the European Union. Thus, most Spanish firms started to invest abroad after the entrance of Spain into the EU. 
the investing firm creates a new entity in the host market, using its own resources and keeping $100 \%$ of its equity.

The knowledge-based view of the firm also considers WOSs as the natural procedure for international expansion (MADHOK [1997]). From this perspective, firms cannot get the same benefits when transferring their capabilities to other firms as when expanding through a WOS. In this sense, both TCT and KBTFs come to the same conclusion. However, the underlying logic used by KBTFs to explain the existence of MNEs is not at all related to opportunism. According to this theory, firms expand through WOSs in order to maximize the value of their knowledge and capabilities. Thus, from the KBTF viewpoint, when firms transfer their capabilities to a local firm instead of exploiting them by themselves, there is a nontrivial loss of value of the assets transferred. This is due to the fact that firm-specific assets are difficult to transfer to other firms: not due to problems of opportunism but rather to problems related to knowledge transfer across firm boundaries (KOGUT AND ZANDER [1993]; MADHOK [1996], [1997]). In effect, firm-specific knowledge is embedded in the organizational routines of the firm and is thus difficult to isolate and transfer to external firms. As CANTWELL [1991] points out, each time a knowledge-based capability is transferred to an external firm, it loses part of its value, as the external firm cannot replicate the original capability easily and perfectly. However, the setting up of a WOS in the host market allows the investing firm to replicate its functioning abroad without losing value in the process.

There are also systemic effects between the capabilities of the firm. For instance, a firm's technology coupled with its brand label can lead to more profits than the same technology with a licensee brand label and reputation (HALLWOOD [1994]). Finally, expanding abroad through WOSs gives firms an opportunity to test and develop new ways of improving their capabilities and knowledge base. Thus, according to MADHOK [1997], exploitation abroad of existing capabilities is not the only reason to set up a WOS; firms can also invest abroad in order to explore new ways to improve their competences and maximize their value.

As we have seen, TCT and KBTFs are competing paradigms to explain the existence and behavior of MNEs. Both lead, however, to the same basic prediction: the natural path of international expansion is through WOSs. Nevertheless, firms often do not proceed in this way. Sometimes, FDIs are made through the (full or partial) acquisition of the equity of a firm previously established in the host country. By so doing, the foreign investor acquires some control rights over the whole package of assets of the acquired firm. Then it can combine those assets with its own firm-specific capabilities. Other times, a greenfield investment is made in cooperation with other partners that provide additional resources. The foreign investor shares the equity of the new entity located in the host country (a JV) with these partners. Although acquisitions and JVs present different organizational characteristics, a common feature of them is that they allow the foreign investor to gain access to assets that other firms have (usually located in the host market) and that are not available through market contracting. In this way, it can be assumed that such assets are firm-specific (like the capabilities owned by the foreign investor). 
Otherwise, it would not make sense to set up a JV or to make an acquisition, as the access to these assets could be obtained with lower TCs through market contracting.

Previous research has analyzed the choice between JVs and acquisitions - both theoretically and empirically - taking into account both TCT and KBTF considerations. Researchers within the TC perspective have analyzed the role of adverse selection and appropriability hazards. BALAKRISHNAN AND KOZA [1993] found that JVs are a means of protecting the firm from adverse selection, that is, of ex ante opportunism related to acquisitions, as it is sometimes difficult to know in advance the value of the target firm. Using a sample of $65 \mathrm{JVs}$ and 165 mergers and acquisitions announced between 1974 and 1977, they analyzed the stock market's reaction to these announcements. They found that the market valued JVs more when the two parent firms belonged to different industries and thus a higher information asymmetry existed. JVs become the most efficient mechanism for coordinating synergistic assets, as they avoid the problems of information asymmetry and adverse selection that would exist in an acquisition. Likewise, in an event study on two-parent JV formation carried out using a sample of 297 domestic and international JVs, REUER AND KOZA [2000] found that only JVs involving asymmetric information generated positive abnormal returns. ${ }^{3}$ Within the TCT tradition, the effect of other factors usually studied as determinants of the ownership structure of foreign subsidiaries has also been analyzed. These factors, such as the desire to protect the investing firm's capabilities and to assume close control of the foreign unit (BUCKLEY AND CASSON [1988]; GATIGNON AND ANDERSON [1988]; GOMES-CASSERES [1989]; HENNART [1988], [1991]; STOPFORD AND WELLS JR. [1972]), or to avoid legal restrictions and political risk, ${ }^{4}$ have also been found to be relevant in the choice between JVs and acquisitions.

Other researchers have focused on problems related to knowledge, people, and routine integration. KogUT AND SINGH [1988] found that cultural distance increased the inherent difficulty of integrating two firms in a single hierarchy. Cultural distance thus forces firms to expand through JVs instead of through acquisitions. These authors carried out an empirical study using a sample of 228 investments made by foreign firms in the United States. Their results show that a greater cultural distance between the home and host countries increased the probability that the investment would be made through a JV or a WOS rather than through an acquisition. HENNART AND REDDY [1997] found that a key factor in the choice between JVs and acquisitions was the so-called digestibility of the foreign firm, i.e., its size and its divisionalization. These authors carried out an empirical study using a sample of 175 FDIs made by Japanese firms in the U.S. through JVs and acquisitions, and concluded that Japanese firms preferred JVs to acquisitions when the U.S. firm was

\footnotetext{
${ }^{3}$ For the purposes of this study, JVs involving asymmetric information were those in which the two parent firms operate in different industries.

4 Among the most recent studies on this topic are those by MELDRUM [2000], PAN [1996], and RAMCHARRAN [2000].
} 
large and not divisionalized. In such cases, it became more difficult to separate desired from undesired assets, and the acquiring MNE had more difficulties in absorbing and integrating the whole package of assets (including undesired assets) of the U.S. partner.

Analyzing the results of previous research, we can see that both information asymmetry and integration problems force firms to choose JVs instead of acquisitions. In particular, cultural distance - a factor that introduces information asymmetry and integration problems - was found to be influential in KOGUT AND SINGH's [1988] paper. Thus, the previous literature indicates that TCT and KBTFs still lead to the same prediction in the choice of entry mode when considering JVs and acquisitions. However, there is one important aspect that remains unexplored in the literature: the determinants of the choice between JVs and the different types of acquisitions. In effect, previous research has mainly analyzed the choice between FAs and JVs, but it has not taken into account the fact that there are different types of acquisitions and that each of these has different implications for the investing firm. Sometimes firms only acquire part of the equity of the target firm. Other times the target firm is jointly acquired by a set of allied firms. As mentioned above, only BARKEMA AND VERMEULEN [1998] have analyzed the entry-mode choice, considering full and partial acquisitions as independent options in their study of the influence of multinational and product diversity on the choice of entry mode.

\section{The Choice of Entry Mode: Joint Ventures, Full Acquisitions, and Partial Acquisitions}

In this section we analyze the choice between JVs, FAs, and PAs from the TCT and KBTF perspectives. Specifically we analyze the effect of national culture on this choice, as that is a factor that can lead to problems of information asymmetry and integration. We also analyze the effect of previous experience in acquisitions. Previous research on acquisition performance showed that experience in acquisitions increases the ability of firms to cope with integration processes. Previous experience may thus mitigate the information asymmetry and integration costs that arise when acquiring a firm in a country with a large cultural distance.

\subsection{The Role of National Culture in the Choice of Entry Mode}

From the TC-information-asymmetry perspective, when investing through acquisitions, the acquiring firm always incurs in an ex ante TC: that derived from the valuation of the firm that it wishes to acquire. The valuation of the target firm takes place in a situation of asymmetric information, which can in turn give rise to an adverse-selection problem. As BALAKRISHNAN AND KOZA [1993] point out, costs derived from asymmetric information and adverse selection are multiplied as the dissimilarity between the acquiring and acquired firms increases. The larger the dissimilarity between the two firms, the larger the difficulty of finding and understanding relevant information and thus the higher the information asymmetry. 
Applying this idea to an international acquisition, it is to be expected that the cultural distance between the home and host countries of the FDI will intensify the dissimilarity between the acquiring and acquired firms. Thus, a large cultural distance aggravates the asymmetric information problems and increases the diseconomy related to the valuation and pricing of the target firm. In conclusion, from the information-asymmetry perspective, valuation problems will increase the preference for JVs over FAs when the cultural distance between the home and host countries increases. According to BALAKRISHNAN AND KOZA [1993], the main advantage of JVs over acquisitions is that the former are a less irreversible means of interorganizational asset combination. FAs imply pooling all the assets of two firms under the same hierarchy from one day to the next and negotiating a price on the target firms' assets before gaining access to them. As most of the relevant assets involved in an acquisition are intangible, it is difficult to identify their real value. This is therefore an important disadvantage. The problem is aggravated in international acquisitions: as the cultural distance increases, it becomes more difficult for the investing firms to get good benchmarks or knowledge to make a proper valuation of these intangible assets. On the other hand, firms investing through JVs have the opportunity to get in touch with these assets or at least to get more precise information in order to value them without having to fully pay for them in advance.

Although there also exists a valuation problem, partners in JVs have several mechanisms to renegotiate the deal or to leave the alliance. Thus, if the investing firm wishes to gain access to the intangible assets of a foreign firm, whose real value is particularly difficult to identify (BALAKRISHNAN AND KOZA [1993]), the JV becomes the most interesting option. ${ }^{5}$ On the basis of this argument, we formulate our first hypothesis:

Hypothesis 1: JVs will be preferred to FAs when the cultural distance between the home and host countries of the FDI is sufficiently large.

However, if we employ the same logic to analyze the choice of PA, this hypothesis cannot be sustained. In a PA, the investing firm does not have to fully pay for the target's assets before gaining access to them. The firm only buys a stake in the target's equity and can, for instance, include an option to acquire the remaining equity at the same price. In such cases, the investing firm will only execute this option when it finds the previous valuation to be accurate. Even when such an option does not exist, PAs allow the foreign investor to protect itself from information asymmetry in a similar way to JVs: its equity position gives the acquiring firm a good position to renegotiate the deal and to get information from the partner. Thus, as firms can protect themselves from information asymmetry when investing through PAs, it can be expected that:

Hypothesis 2a: JVs will not become preferred to PAs as cultural distance increases.

\footnotetext{
5 JVs also protect the acquiring firm against uncertainty. See KoGUT [1991].
} 
When analyzing the choice between JVs and acquisitions, KBTF also deals with the costs of acquisition, although attention is now focused on their ex post costs: those derived from the integration of the acquired and acquiring companies. Within this context, the cultural distance between the home and host countries increases the difficulty of the integration process. However, national cultural distance is not the only cultural barrier that may exist. There is corporate cultural distance as well. Thus, firms investing through acquisitions have to make a double effort in order to gain access to local firm-specific resources, bridging the gaps between both the national and the corporate cultures of the investing and target firms. This is what BARKEMA, BELL, AND PENNINGS [1996] call double-layered acculturation. Employing the concept of organizational fit (JEMISON AND SITKIN [1986, p. 147]), defined as "the match between administrative practices, cultural practices and personal characteristics of the acquiring and acquired firms," KoGUT AND SINGH [1988] show how the difficulty of managing the personnel of an acquired company increases with cultural distance, as a result of the difficulty of integrating the administrative systems of the acquiring and acquired companies.

Obviously firms investing through JVs also have to cope with this problem. In JVs, however, the management and monitoring of the local labor force and dealings with clients and suppliers may be entrusted to the local partner, who possesses the necessary local knowledge and the appropriate incentives to carry out these tasks (Kogut AND Singh [1988], HenNART AND REDDY [1997]). An additional disadvantage the investing firm must overcome when investing through acquisitions, but not when investing through JVs, is organizational inertia (BARKEMA AND VERMEULEN [1998]). When acquiring a foreign firm, the investing firm may encounter problems in transferring its own routines to the foreign unit, because of (conscious and unconscious) resistance to change in the acquired firm. As a consequence of the acquisition, the acquired firm's personnel must change their routines and procedures, and this is difficult to implement from day one.

This problem is less important in the case of greenfield JVs, as the new entity does not have a background as an organization of previous routines and corporate culture. As pointed out by BETTIS AND PRAHALAD [1995, p. 10], "new ventures do not have the problem of having to run down an unlearning curve in order to be able to run up a learning curve." A greenfield JV allows the foreign investor to transfer its own distinctive competences to the new venture from the outset, without having to wait for the local firm to run down the aforementioned unlearning curve. In addition, when investing through JVs, the foreign firm can also negotiate and identify the optimal combination of national and corporate cultures together with the local partner.

According to CHILD AND FAULKNER [1998], partners in JVs have three main options in defining the new culture of the venture: synergy (the setting up of a new culture emerging from the combination of both parent firms' cultures); segregation (the coexistence of the previous cultures, each one in an isolated area, for instance, the local one in marketing and that of the foreign firm in manufacturing); and domination (the prevalence of the culture of only one of the parents). Whereas 
partners in JVs have the incentives and negotiating mechanisms to find the optimal solution, firms investing through acquisitions may face more problems in identifying this optimal solution - due mainly to the aforementioned resistance to change.

Thus, from a KBTF perspective, we can expect an increasing national cultural distance to increase the preference for JVs over acquisitions. However, if we take into account the existence of PAs as an option, the situation is completely different. The equity position of the local partner in a JV is an incentive for him to cooperate in order to identify the optimal combination of resources, administrative systems, and corporate culture. However, the equity position of a local shareholder in the target firm may be an obstacle to the handling of the acquisition process. In JVs, local resources and employees that are not transferred to the JV remain within the boundaries of the local partner.

In the case of acquisitions, however, resources and people that do not fit within the interests of the acquiring firm have to be sold and fired, respectively. This fact usually leads to political processes in the target firm, which may be aggravated in the case of PAs. The existence of a local shareholder in the acquired firm's equity may be an obstacle, as he may not be interested in firing some employees or divesting in some areas. Thus, factions may be formed around the local shareholder and the foreign investing firm, respectively, blocking the effective integration of the two firms. The equity position of the local partner may also give him authority to nominate executives who are not well trained in the foreign firm's technologies or systems and that are unable to manage them effectively. On the other hand, if the foreign firm had $100 \%$ of the equity, it would hire only local managers when necessary.

Both problems increase with cultural distance. When cultural distance increases, the ability of the personnel of the target firm to absorb and exploit the foreign investor's know-how and routines decreases (MADHOK [1997, p. 49]). Thus, the amounts of local resources, managers, and personnel that meet the foreign investor's needs decrease. In such cases, FAs and JVs are more favorable options for the foreign investor than PAs. In the first case, the acquiring firm is free to proceed with the necessary restructuring of the foreign unit. In the second, the local firm only transfers to the JV the appropriate local managers and resources without having to restructure its own organization. Thus, in accordance with KBTF we predict that:

Hypothesis 2b: JVs and FAs will become preferred to PAs as cultural distance increases.

\subsection{The Role of Previous Experience in the Management of Acquisitions}

Although acquisitions involve relevant postintegration costs, it seems reasonable to assume that these costs will be dependent on the acquiring firm's ability to handle the integration process. This ability will in turn be dependent on its previous experience managing acquisitions. In fact, ZOLLO AND SINGH [1998] found that prior experience in acquisitions positively affected the performance of the acquisition. 
This is because firms that have previously carried out acquisitions have developed and codified experience that they can use to successfully confront future acquisitions, which ultimately increases the likelihood of these firms investing through an acquisition again.

There is some empirical evidence to support this hypothesis in the field of international management: CAVES AND MEHRA [1986] found that firms with a stronger multinational nature showed a larger tendency towards acquisitions than towards the establishment of WOSs. The greater the firm's multinationality, the greater its ability to avoid the risks and costs of investing through acquisitions. These firms have not only standardized the transferring process of their distinctive competences (HENNART AND REDDY [1997]), but also developed some organizational routines for integrating acquired firms and dealing with subsidiaries of different nationalities (KOGUT AND SINGH [1988]). On the basis of this idea, we formulate the following hypothesis:

Hypothesis 3: Acquisitions will be preferred to JVs when the investing firm has accumulated prior acquisitions experience.

\section{Test of the Theory}

\subsection{Data Features}

In order to test the previously formulated hypotheses, we used a database (DB) of FDIs carried out by Spanish firms. This DB was obtained from a wider one compiled by one of the authors of this paper, as part of a broader research project, from news items about FDIs made by Spanish firms published in Expansion, the leading economic newspaper in Spain. ${ }^{6}$ This DB comprises 108 FDIs made by Spanish firms through JVs and full or partial acquisitions from 1988 to 1996, inclusive. The Spanish investors are firms listed on the Madrid Stock Market. Of these investments, 46 took the form of JVs, whereas the remaining 62 gave rise to different types of acquisitions - 21 FAs and 41 PAs.

When collecting the press clippings relative to the Spanish FDIs, we noticed the existence of two different kinds of PAs: those that we have called pure PAs (PPAs), and those that have been termed shared PAs (SPAs). A PPA arises when the acquiring firm buys just a part of the equity of a company located in the host market. Thus, the acquisition involves only two firms: the acquiring firm and the partially acquired one. On the other hand, an SPA arises when two or more different firms (which usually come from different countries) jointly acquire a third firm located in the host market. An SPA thus requires a previous collaboration agreement between the different acquiring companies and hence entails two different, consecutive processes: the establishment of a cooperative agreement and the process

\footnotetext{
6 This wider database comprises all FDIs made by Spanish firms and published by the economic press in the period of study, not only those made by firms listed on the Madrid Stock Exchange - see LóPEZ-DuARTE AND GARCÍA-CANAL [2001].
} 
of acquisition. Of the 41 PAs mentioned above, 26 are PPAs, while the remaining 15 are SPAs.

For every FDI, we collected information relative to the ownership structure of the foreign unit, the way it was set up, and the foreign investor, all of which was obtained from annual reports.

\subsection{Dependent Variables and Method of Analysis}

Our interest in adopting different ways of internationalization led us to use qualitative dependent variables. This in turn led us to estimate several logit models to test the previously formulated hypotheses.

As a first step, in order to study factors influencing the choice between JVs, FAs, and PAs when investing abroad, we used a dependent variable with three categories, valued 0 when the FDI was made through a JV, 1 when it was made through the acquisition of $100 \%$ of the equity of a firm established in the host market, and 2 when it gave rise to a PA. Subsequently, in order to analyze the differences between PPA and SPA in an exploratory way, we used a dependent variable with four categories: JVs (0), FAs (1), pure PAs (2), and shared PAs (3).

Using these variables, we estimated multinomial logit models, where the probability that the investment was made through an acquisition is explained by the independent variables defined below. In multinomial logit models, the estimated coefficients measure the effect of the variation of the independent variable on the relative probability that the dependent variable will take a particular value. In other words, it is not so much the effect on the probability itself that the dependent variable will take a particular value that is estimated, but rather the effect on the excess of this probability over the probability that the variable will take another value, which is used as a reference - in this particular case we took the value 0 as reference. In multinomial models, $n-1$ coefficients are estimated for each independent variable, where $n$ is the number of categories of the dependent variable. ${ }^{7}$ These coefficients indicate the (positive or negative) effect of an increase in the independent variable on the relative probability of investing through a full, pure partial, or shared partial acquisition versus the creation of a JV. For instance, a positive sign for a coefficient associated with an independent variable and with the option of FA indicates that the probability of adopting such an entry mode rather than the creation of a JV increases with increasing values of the independent variable. Thus, the hypotheses are considered to be accepted when the sign of the coefficient associated with every independent variable coincides with the expected sign, and these coefficients are statistically significant.

The estimates were obtained by using the logit procedure of the limdep statistical package.

\footnotetext{
${ }^{7}$ It should be noted that it is unnecessary to sort these categories (ALDRICH AND NELSON [1984]).
} 


\subsection{Independent Variables}

To test the hypotheses related to the cultural distance between the home and host countries (Hypotheses 1, 2a, and 2b), we used KoGUT AND SINGH's [1988] composite index based on Hofstede's measures of cultural distance. These measures are related to four cultural dimensions: individualism, power distance, uncertainty avoidance, and masculinity (HOFSTEDE [1980]). From the TCT perspective, the effect of the cultural distance between the home and host countries on the preference for JVs over FAs will not exist for PAs. However, from the KBTF perspective it is to be expected that the negative effect of cultural distance will be particularly strong for PAs. A large cultural distance will thus increase the preference for JVs and even FAs over PAs.

With respect to Hypothesis 3, we used the variable acqnum, which is the number of prior (full or partial) acquisitions made by the investing firm during the period of study. This variable measures the acquisition experience of the investing firm. It is thus to be expected that the probability that the FDI is made through an acquisition (full or partial) is higher when the foreign investor has accumulated prior acquisition experience.

Several control variables were also included in the study.

Firstly, in order to control the influence of the value of the resources and capabilities of the investing firm on the choice of entry mode, we used Tobin's $q$ ratio. This is the market-to-book ratio of the value of the assets of the Spanish investing company on 31 December of the year immediately before the FDI was made. As stated in the literature (see footnote 4), sharing the ownership of the international venture implies the risk that the accrued distinctive competences of the foreign investor will be spread: although the investing firm gains access to the knowledge the partner has about the local market, the latter also has direct access to the capabilities of the investor. The risks assumed by the foreign investor increase with the importance of its capabilities, as they fall within the reach of and can be assimilated by the partner. The higher the degree of accumulation of distinctive competences by the foreign investor, the higher the costs of using an entry mode that implies sharing the ownership.

In order to control the influence on the entry-mode choice of the country risk affecting the host country, we used three dummy variables: CR1, CR2, and CR3. Using these variables, we grouped countries into homogeneous blocks that present a similar country risk for Spanish investors. Our categories are concordant with those of CESCE,${ }^{8}$ which is the only Spanish company that offers protection against political risk to Spanish foreign investors. ${ }^{9}$ As other studies have shown, the higher the country risk affecting the host country, the higher the preference for sharedequity entry modes.

\footnotetext{
8 Compañía Española de Seguro de Crédito a la Exportación.

9 See the annual reports of CESCE for the period of study.
} 
Table 1

Correlation Matrix

\begin{tabular}{cccccccccc|c}
\hline hofind & acqexp & Tobin's $q$ & CR2 & \multicolumn{1}{c}{ CR3 } & size & service & regsec & const & finance & \\
\hline \multirow{2}{*}{1.000} & 0.014 & 0.086 & 0.006 & $-0.390^{* *}$ & -0.033 & -0.154 & 0.184 & 0.025 & 0.054 & hofind \\
& 1.000 & 0.006 & 0.173 & 0.095 & 0.183 & -0.070 & -0.042 & -0.150 & $0.275^{* *}$ & acqexp \\
& & 1.000 & -0.166 & -0.029 & 0.019 & $0.252^{* *}$ & -0.045 & -0.162 & -0.184 & Tobin's $q$ \\
& & & 1.000 & $-0.384^{* *}$ & -0.021 & -0.171 & -0.053 & -0.049 & 0.141 & CR2 \\
& & & & 1.000 & $0.256^{* *}$ & 0.016 & 0.045 & 0.051 & -0.113 & CR3 \\
& & & & & 1.000 & $-0.192^{*}$ & $0.583^{*}$ & -0.169 & 0.106 & size \\
& & & & & & 1.000 & -0.167 & -0.079 & -0.141 & service \\
& & & & & & & 1.000 & $-0.191^{*}$ & $-0.339^{* *}$ & regsec \\
& & & & & & & & 1.000 & -0.161 & const \\
\hline \multirow{2}{*}{0.2} & 0.0 & 0.1 & 0.0 & 0.0 & 1030.0 & 0.0 & 0.0 & 0.0 & 0.0 & Minimum \\
3.3 & 6.0 & 5.3 & 1.0 & 1.0 & 3211619.4 & 1.0 & 1.0 & 1.0 & 1.0 & Maximum \\
0.864 & 0.972 & 1.377 & 0.296 & 0.259 & 533344.1 & 0.0064 & 0.287 & 0.0073 & 0.000 & Mean \\
0.731 & 1.519 & 0.707 & 0.459 & 0.440 & 722592.0 & 0.247 & 0.454 & 0.278 & 0.418 & Standard dev. \\
\hline
\end{tabular}

We also used a number of sectorial variables to control the influence of the industry group on the form of investment: construction equals 1 for FDIs (9) carried out in the construction sector, manufacturing equals 1 for FDIs (37) carried out in the manufacturing sectors, regsec equals 1 for FDIs (31) carried out in activity sectors that have traditionally been regulated and are now being increasingly deregulated, such as air transport, communications, and energy (OECD [1993]), service equals 1 for FDIs (7) carried out in the service (nonfinance) sectors - except for those included in the regsec variable, and finance equals 1 for FDIs (24) carried out in the financial services sector. Finally, the variable size - the turnover of the foreign investor in the year immediately prior to the $\mathrm{FDI}^{10}$ (inflation-adjusted) - was included in the study as control variable. CR1 and manufacturing act as reference in this study.

Table 1 presents the correlation matrix of the variables used in the empirical tests as well as descriptive features for each variable - maximum, minimum, mean, and standard deviation.

\subsection{Results}

The empirical tests of the hypotheses formulated above were carried out in two stages. Firstly, a multinomial logit model was estimated that considers the JV and the two entry modes a firm can choose when investing abroad through an acquisition: full and partial acquisitions (Table 2). Secondly, in order to analyze the differences between the two different types of PAs, a multinomial logit model with four categories was estimated (Table 3). The tables show the values, for each model, of the coefficients of the independent variables, their standard errors, and an indication of their levels of significance. Generally speaking, it can be observed that the different models offer estimates that are statistically significant - chi-

10 This information was obtained from the annual report published by DUNS 50,000. 
squared $<0.001-$ and the different observations may be satisfactorily classified at percentages larger than $69.5 \%$.

Taken as a whole, our results confirm the hypothesis with regard to the effect of the accrued experience related to a particular entry mode, as well as the knowledge-based view predictions concerning the effect of cultural distance on the choice of PAs. The results corresponding to each particular hypothesis are as follows:

Hypothesis 1, relative to the influence of cultural distance on the choice between JVs and FAs: Rejected. The hofind variable, measuring the cultural distance between the home and host countries of the FDI, presents the appropriate sign but is not statistically significant in any of the models estimated.

Hypothesis 2, relative to the influence of cultural distance on the choice of PAs as entry mode: This hypothesis was decomposed into two different and opposing subhypotheses. The first one (Hypothesis 2a), based on TCT, postulated a weaker effect of the cultural distance for PAs than for FAs. Hypothesis $2 b$, based on KBTF, postulated exactly the opposite. The results of hofind in Tables 2 and 3 allow us to reject Hypothesis 2a and confirm Hypothesis $2 \mathrm{~b}$ : hofind presents a negative and statistically significant coefficient for PAs, but not for FAs, in all the multinomial models estimated.

Hypothesis 3 relative to the influence of the experience accrued by the firm relative to a particular entry mode: Confirmed. acqexp shows the expected sign and is statistically significant in all the models estimated.

\subsection{Discussion}

As mentioned above, our results allowed us to confirm the influence of cultural distance and accrued experience on the choice between JVs and different types of acquisitions.

With regard to the influence of the cultural distance between the home and host countries on the choice of entry mode, it is possible to identify different results. Firstly, it seems that cultural distance does not influence the choice between JVs and FAs - the hofind variable presents the appropriate sign in Table 2, which displays the results relative to the first multinomial logit model (JV-FA-PA), but it is not statistically significant. This is an unexpected result, contrary to that achieved by KogUT AND SINGH [1988], and one that does not allow us to confirm Hypothesis 1.

We found that while JVs are preferred to PAs as cultural distance increases, they are not preferred to FAs. In fact, we found that when cultural distance increases, firms tend to make one of two opposing choices: greenfield JVs or FAs. These two choices are driven by two distinct strategies: profiting from local management knowledge and culture, or replicating foreign investors' routines and culture. When forming JVs, firms benefit from having a motivated partner that helps the foreign firm to combine local and foreign resources within a shared governance structure. When choosing FAs, firms protect themselves against value destruction caused by 
Table 2

Multinomial Logit Model Estimates

[beta coefficient values (standard deviation bracket)] Cases: 108 $(0=\mathrm{JV}, 1=\mathrm{FA}, 2=\mathrm{PA})$

\begin{tabular}{cccc}
\hline $\begin{array}{c}\text { Variable } \\
\text { name }\end{array}$ & Description & $\begin{array}{c}\text { Full } \\
\text { acquisition }\end{array}$ & $\begin{array}{c}\text { Partial } \\
\text { acquisition }\end{array}$ \\
\hline \multirow{2}{*}{ hofind } & Cultural distance index based & -0.1774 & $-0.9647^{* *}$ \\
& on Hofstede's measures & $(0.4495)$ & $(0.4817)$ \\
acqexp & Number of FDIs made through & $1.6194^{* * *}$ & $1.6115^{* * *}$ \\
& acquisitions by the investing & $(0.4662)$ & $(0.4408)$ \\
& $\quad$ firm prior to the FDI & & \\
Tobin's $q$ & identified in the database & $1.075^{* *}$ & 0.4317 \\
& Value of Tobin's q ratio & $(0.5463)$ & $(0.4733)$ \\
CR2 & FDIs located in countries included & $-1.6530^{* *}$ & -1.0484 \\
& in group 2 by CESCE due to & $(0.8054)$ & $(0.7095)$ \\
their level of country risk & & $-1.5655^{* *}$ \\
CR3 & FDIs located in countries included & $-3.7060^{* * *}$ & $(0.7893)$ \\
& in group 2 by CESCE due to & $(1.342)$ & \\
size & their level of country risk & & $-0.5706 \times 10^{-6}$ \\
& Turnover of the foreign investor & $0.1559 \times 10^{-6}$ & $\left(0.4906 \times 10^{-6}\right)$ \\
service & FDIs carried out in service sectors & -2.5934 & -0.9529 \\
& & $(1.613)$ & $(1.134)$ \\
regsec & FDIs carried out in regulated sectors & -1.7215 & 0.2415 \\
& & $(1.212)$ & $(0.8398)$ \\
const & FDIs carried out in the construction & -1.2038 & -12.445 \\
& sector & $(1.234)$ & $(206.7)$ \\
& FDIs carried out in the financial & $-1.7629^{*}$ & -0.1872 \\
& services sector & $(0.9984)$ & $(0.8144)$ \\
\hline
\end{tabular}

Key: chi-squared $69.332^{* * *}$. Observations satisfactorily classified: $71.3 \%$.

${ }^{*} p<0.1 ;{ }^{* *} p<0.05$; *** $p<0.01$.

cultural incompatibility (MADHOK [1997]). It seems that firms that choose PAs are stuck in the middle, having a local investor in the equity of the foreign unit that is not so committed and motivated to find the proper combination of local and foreign resources as a partner in a JV is. Thus, PAs aggravate the double-layered acculturation problems through the addition of two different kinds of problems: those derived from the integration of the acquired and acquiring firms in one single hierarchy, and those derived from the permanence of a partner in the equity of the acquired firm. 
Table 3

Multinomial Logit Model Estimates

[beta coefficient values (standard deviation bracket)] Cases: 108 $(0=\mathrm{JV}, 1=\mathrm{FA}, 2=\mathrm{PPA}, 3=\mathrm{SPA})$

\begin{tabular}{|c|c|c|c|c|}
\hline Variable name & Description & FA & PPA & SPAs \\
\hline hofind & $\begin{array}{l}\text { Cultural distance index based } \\
\text { on Hofstede's measures }\end{array}$ & $\begin{array}{l}-0.3903 \\
(0.4788)\end{array}$ & $\begin{array}{c}-0.4815^{* *} \\
(0.5888)\end{array}$ & $\begin{array}{l}-0.1440 \\
(0.6786)\end{array}$ \\
\hline acqexp & $\begin{array}{l}\text { Number of FDIs made through } \\
\text { acquisitions by the investing } \\
\text { firm prior to the FDI identified } \\
\text { in the database }\end{array}$ & $\begin{array}{r}2.0275^{* * *} \\
(0.5531)\end{array}$ & $\begin{array}{c}2.1460^{* * *} \\
(05231)\end{array}$ & $\begin{array}{c}1.3170^{* * *} \\
(0.4920)\end{array}$ \\
\hline Tobin's $q$ & Value of Tobin's $q$ ratio & $\begin{array}{l}1.5081^{* *} \\
(0.6069)\end{array}$ & $\begin{array}{l}1.0883^{*} \\
(0.6268)\end{array}$ & $\begin{array}{c}0.0634 \\
(0.6218)\end{array}$ \\
\hline $\mathrm{CR} 2$ & $\begin{array}{l}\text { FDIs located in countries } \\
\text { included in group } 2 \text { by CESCE } \\
\text { due to their level of country risk }\end{array}$ & $\begin{array}{c}-2.1722^{* *} \\
(0.8731)\end{array}$ & $\begin{array}{c}-2.0031^{* *} \\
(0.8503)\end{array}$ & $\begin{array}{l}0.6313 \\
(1.061)\end{array}$ \\
\hline CR3 & $\begin{array}{l}\text { FDIs located in countries } \\
\text { included in group } 2 \text { by CESCE } \\
\text { due to their level of country risk }\end{array}$ & $\begin{array}{c}-4.8225^{* * *} \\
(1.506)\end{array}$ & $\begin{array}{c}-3.8319^{* * *} \\
(1.192)\end{array}$ & $\begin{array}{l}0.4527 \\
(1.087)\end{array}$ \\
\hline size & Turnover of the foreign investor & $\begin{array}{c}0.3141 \times 10^{-6} \\
\left(0.6605 \times 10^{-6}\right)\end{array}$ & $\begin{array}{c}0.2103 \times 10^{-6} \\
\left(0.5670 \times 10^{-6}\right)\end{array}$ & $\begin{array}{c}-0.1928 \times 10^{-5 * *} \\
\left(0.8666 \times 10^{-6}\right)\end{array}$ \\
\hline service & $\begin{array}{l}\text { FDIs carried out in service } \\
\text { sectors }\end{array}$ & $\begin{array}{c}-4.7618^{* *} \\
(2.056)\end{array}$ & $\begin{array}{c}-15.061 \\
(202.5)\end{array}$ & $\begin{array}{l}1.8373 \\
(1.379)\end{array}$ \\
\hline regsec & $\begin{array}{l}\text { FDIs carried out in regulated } \\
\text { sectors }\end{array}$ & $\begin{array}{c}-2.3163^{*} \\
(1.269)\end{array}$ & $\begin{array}{c}-1.1919 \\
(1.056)\end{array}$ & $\begin{array}{l}2.1561^{*} \\
(1.164)\end{array}$ \\
\hline const & $\begin{array}{l}\text { FDIs carried out in the } \\
\text { construction sector }\end{array}$ & $\begin{array}{c}-1.2201 \\
(1.265)\end{array}$ & $\begin{array}{c}-12.610 \\
(316.1)\end{array}$ & $\begin{array}{c}-11.686 \\
(312.1)\end{array}$ \\
\hline finance & $\begin{array}{l}\text { FDIs carried out in the } \\
\text { financial services sector }\end{array}$ & $\begin{array}{l}-2.2315^{* *} \\
(1.077)\end{array}$ & $\begin{array}{c}-1.4246 \\
(1.030)\end{array}$ & $\begin{array}{l}1.8994 \\
(1.194)\end{array}$ \\
\hline
\end{tabular}

Key: chi-squared $97.607^{* * *}$. Observations satisfactorily classified: $68.5 \%$.

${ }^{*} p<0.1$; ${ }^{* *} p<0.05$; ${ }^{* * *} p<0.01$.

This result seems to be contrary to that achieved by BARKEMA AND VERMEULEN [1998]. In the cited study, these authors found that a larger cultural distance positively affects the tendency to invest through shared ventures (JVs or joint acquisitions). However, the results of the multinomial logit model including four categories (JV, FA, PPA, SPA) may shed light on this debate. The results presented in Table 3 demonstrate that the two different types of PAs are very differently affected by the cultural distance: while there is a clear preference for JVs over PPAs as cultural distance increases, there is no such preference when the PA is an SPA. As an SPA requires a collaboration agreement among the different acquiring firms prior to the acquisition, this option may become an entry mode that is more like a JV than like an acquisition. This is because the set of acquiring partners has more freedom to deal with the integration process.

Our results show an evidently different influence of cultural distance on the choice of the two different types of PAs. Thus, according to BARKEMA AND VERMEULEN's [1998] findings, JVs and SPAs become more interesting options 
as the cultural distance between the home and host countries of the FDI increases. In contrast, the negative effect of cultural distance seems to be aggravated when investing through a PPA. This therefore becomes the least advisable entry mode in countries with a large cultural distance.

Summing up our results with respect to cultural distance, we can see that information asymmetry is not a good perspective to explain the choice between JVs and acquisitions. As PAs allow the foreign investor to deal with information asymmetry problems, we would expect them also to become preferred when the cultural distance increases. However, they do not, because this option aggravates integration problems. Thus, in accordance with HENNART AND REDDY's [2000] insight, an analysis of PAs has shed light on the information-asymmetry versus digestibility debate. The integration problems associated with acquisitions are more important than information-asymmetry problems when choosing between JVs and acquisitions.

As to the empirical verification of Hypothesis 3 relative to prior experience in acquisitions, the acqnum variable presents the appropriate sign and is statistically significant in all the models estimated. As mentioned above, firms that have accumulated experience in previous acquisitions have standardized the transfer of their distinctive competences and developed a number of organizational routines for integrating acquired firms, thus making acquisitions a more attractive option. According to HALEBLIAN AND FINKELSTEIN [1999], the value of the acquisition experience is particularly high when making similar acquisitions, as for instance those made in the same activity sector. ${ }^{11}$ The effect of accrued experience seems to affect FA and PA equally, irrespective of whether the PA is a PPA or an SPA.

The results relative to control variables confirm the differences between FAs and PAs, on the one hand, and between PPAs and SPAs, on the other. Those relating to Tobin's $q$ variable confirm that PPAs are similar entry modes to FAs, while SPAs are much more similar to JVs. The results of this variable shown in Table 3 confirm that the higher the accumulation degree of competences of the foreign investor, the higher the tendency to invest through FAs or through PPAs, but not through SPAs. In an SPA, as in a JV, there is at least one partner with whom the acquiring firm must not only share control of the unit located in the host country, but also cooperate in order to be able to carry out the joint acquisition. Consequently, SPAs present the inconvenience, in comparison with FAs (and even with PPAs), that the firm-specific competences of the foreign investor are not so well protected, as there exists a partner who has access to these competences.

The results on country-risk variables also confirm the existing difference between FAs and the different types of PAs. The higher the country risk affecting the host country, the higher the tendency to invest through JVs and SPAs instead of FAs or PPAs.

\footnotetext{
11 The acquiring and acquired firms compete in the same activity sector in all the acquisitions registered in the DB.
} 


\section{Conclusions}

In this paper we have analyzed the choice between JVs, FAs, and PAs when investing abroad. For the purposes of the study, an FA takes place when the investing firm acquires $100 \%$ of the target's equity, while a PA is an acquisition (by just one firm or by several firms) of a part of the equity of a firm previously located in the host market. We expected this choice to be conditioned by TC factors (particularly the cultural distance between the home and host countries), as well as by the previous experience and internationalization path of the foreign investor, as suggested by the KBTFs. We have also analyzed different types of PAs (pure partial acquisitions and shared partial acquisitions) as alternative entry modes to JVs and FAs. A PPA is one in which the acquiring firm buys just a part of the equity of a company located in the host market. The acquisition process thus only involves two firms: the acquiring firm and the partially acquired one. On the other hand, an SPA is one in which two or more different firms (which usually come from different countries) jointly acquire a third firm located in the host market.

Our results thus confirm HENNART AND REDDY's [2000] insight with respect to the need to study PAs as a different entry mode to FAs. Analyzing the influence of information asymmetry and digestibility problems (BALAKRISHNAN AND Koza [1993], HeNNART AND REDDy [1997], REUER AND KoZA [2000]), they claim that a study of PAs as an entry mode would shed light on which of these two factors is more important. This is because PAs allow the foreign investor to deal with information-asymmetry problems, although they also entail digestibility and postintegration problems. When confronting both problems in the same entry mode, our results show that firms prefer to avoid postintegration problems rather than cope with information-asymmetry problems. These results thus show that PAs, and in particular PPAs, are the least advisable option when a large cultural distance exists between the home and host countries. The integration problems that always exist in acquisitions made in environments at a large cultural distance seem to be aggravated in the case of PPAs. When investing through a PPA, the investing firm is not free to carry out the integration of cultures of the acquiring and acquired firms. This is due to the existence of a local partner in the acquired firm's equity and to the need to negotiate the integration process with this partner.

These results therefore shed light on the information-asymmetry-digestibility debate (HENNART AND REDDY [2000], REUER AND KoZA [2000]). It seems that cultural distance influences both the problem of information asymmetry and that of integration and digestibility related to international acquisitions.

Our results also show that the previous experience of the foreign investor conditions the choice, as past experience with acquisitions helps to reduce postacquisition costs, thus making this option more attractive. Even though it would appear that acquisitions become less advisable options as the firm aims at more culturally distant countries, previous experience may imply that this option is still valid. Thus, it is 
not only the target firm's characteristics that influence the choice of entry mode, but also the experience accrued by the investing firm in the management and transfer of these capabilities.

Certain limitations in the study must be taken into account when analyzing our results. Firstly, the results may be influenced by the particular characteristics of our sample: all the FDIs collected in the DB were made by Spanish firms. As these firms started investing abroad only very recently (due to legal and political factors), their entry-mode choice is probably influenced by their lack of experience in international markets. Nevertheless, the use of this data may shed light on the entry-mode debate when the investing firms come from countries that are to be found at a medium stage of the investment development path.

Another limitation is that it was not possible to measure the digestibility of the target firm as HENNART AND REDDY [1997] did, nor to measure the concentration degree of the sector in the host country. The wide range of different host countries collected in our sample (32) made it impossible to get homogeneous data with respect to these variables. Cultural distance is, however, a factor traditionally associated with digestibility, and its influence is analyzed in this study.

It seems, therefore, that further research using large, international samples of FDIs is needed in order to reach conclusions that can be generalized to all types of FDIs, irrespective of the investing firm's host country.

\section{References}

ARrow, K. J. [1962], "The Economic Implications of Learning by Doing," Review of Economic Studies, 29, 153-173.

AlDRICH, J. H., AND F. D. Nelson [1984], "Linear Probability, Logit, and Probit Models," Sage University Paper Series on Quantitative Applications in the Social Sciences 07-045, Beverly Hills, CA.

BALAKRISHNAN, S., AND M. KoZA [1993], "Information Asymmetry, Adverse Selection, and Joint Ventures: Theory and Evidence," Journal of Economic Behavior and Organization, 20, 99-117.

Barkema, H., J. H. Bell, AND J. M. Pennings [1996], "Foreign Entry, Cultural Barriers, and Learning," Strategic Management Journal, 17, 151-166.

- - AND F. VERMEULEN [1998], "International Expansion through Start-Up or Acquisition: A Learning Perspective," Academy of Management Journal, 41, 7-26.

BetTis, R. A., AND C. K. PRAhALAd [1995], "The Dominant Logic: Retrospective and Extension," Strategic Management Journal, 16, 5-14.

BuCKLEY, P. J., AND M. CASSON [1976], The Future of the Multinational Enterprise, McMillan: London.

- - AND - - [1988], "A Theory of Cooperation in International Business," pp. 31-53 in: F. J. Contractor and P. Lorange (eds.), Cooperative Strategies in International Business, Lexington Books: Lexington, MA.

Cantwell, J. [1991], "The Theory of Technological Competence and its Application to International Production,” pp. 33-67 in: D. McFridge (ed.), Foreign Investment, Technology, and Economic Growth, University of Calgary Press: Calgary.

CAves, R. E., AND S. K. Mehra [1986], "Entry of Foreign Multinationals into U.S. Manufacturing Industries," pp. 449-481 in: M. Porter (ed.), Competition in Global Industries, Harvard Business School Press: Boston, MA. 
CHI, T. [1994], "Trading in Strategic Resources: Necessary Conditions, Transaction Cost Problems, and Choice of Exchange Structure," Strategic Management Journal, 15, 271290.

ChILD, J., AND D. FAULKNer [1998], Strategies of Cooperation: Managing Alliances, Networks, and Joint Ventures, Oxford University Press: New York.

GAtignon, H., AND E. ANDERSON [1988], "The Multinational's Degree of Control over Foreign Subsidiaries: An Empirical Test of a Transaction Cost Explanation," Journal of Law, Economics, and Organization, 4, 305-994.

Gomes-CASSERES, B. [1989], "Ownership Structure of Foreign Subsidiaries: Theory and Evidence," Journal of Economic Behavior and Organizations, 11, 1-25.

Haleblian, J., AND S. FinKelstein [1999], "The Influence of Organizational Acquisition Experience on Acquisition Performance: A Behavioral Learning Perspective," Administrative Science Quarterly, 44, 29-56.

HaLlwoOd, C. P. [1994], "An Observation on the Transaction Cost Theory of the (Multinational) Firm," Journal of Institutional and Theoretical Economics, 150, 351-361.

HENNART, J. F. [1982], A Theory of Multinational Enterprise, University of Michigan Press: Ann Arbor, MI.

- - [1988], "A Transaction Cost Theory of Equity Joint Ventures," Strategic Management Journal, 9, 361-374.

- - [1991], "The Transaction Cost Theory of Joint Ventures: An Empirical Study of Japanese Subsidiaries in the United States," Management Science, 37, 483-497.

- - AND J. LARIMO [1998], "The Impact of Culture on the Strategy of Multinational Enterprises: Does National Origin Affect Ownership Decisions?" Journal of International Business Studies, 29, 515-538.

- - AND S. REDDY [1997], "The Choice between Mergers/Acquisitions and Joint Ventures: The Case of Japanese Investors in the United States," Strategic Management Journal, $18,1-12$.

- - AND - - [2000], "Digestibility and Asymmetric Information in the Choice between Acquisitions and Joint Ventures: Where's the Beef?" Strategic Management Journal, 21, 191-194.

Hofstede, G. [1980], Culture's Consequences: International Differences in Work Related Values, Sage: Beverly Hills, CA.

Jemison, D. B., AND S. B. SitKin [1986], “Corporate Acquisition: A Process Perspective,” Academy of Management Review, 11, 145-163.

Kogut, B. [1991], "Joint Ventures and the Option to Expand and Acquire," Management Science, 37, 19-33.

- - AND H. SingH [1988], "The Effect of National Culture on the Choice of Entry Mode," Journal of International Business Studies, 19, 411-432.

- - AND U. ZANDER [1993], "Knowledge of the Firm and the Evolutionary Theory of the Multinational Corporation," Journal of International Business Studies, 24, 625-645.

- - AND - - [1995], "Knowledge, Market Failure, and the Multinational Enterprise: A Reply," Journal of International Business Studies, 26, 417-426.

LÓPEZ-DuARTE, C., AND E. GARCíA-CANAL [2001], "Empresas Conjuntas o Adquisiciones en el Proceso de Inversión Exterior," Revista de Economía Aplicada, 26, 5-28.

MadHOK, A. [1996], "The Organization of Economic Activity: Transaction Costs, Firm Capabilities, and the Nature of Governance," Organization Science, 7, 577-590.

- - [1997], "Cost, Value, and Foreign Market Entry Mode: The Transaction and the Firm," Strategic Management Journal, 18, 39-61.

Meldrum, D. [2000], "Country Risk and Foreign Direct Investment," Business Economics, $35,33-41$.

OECD [1993], "Recent Developments in Foreign Direct Investment: A Sectorial Analysis," Financial Market Trends, February, 67-86. 
PAN, Y. [1996], "Influences on Foreign Direct Investment Equity Ownership Level in Joint Ventures in China," Journal of International Business Studies, 27, 1-26.

RAMCharRan, H. [2000], "Foreign Direct Investment in Central and Eastern Europe: An Analysis of Region and Country Risk Factors," American Business Review, 18, 1-8.

REUER, J. J., AND M. P. KOZA [2000], "On Lemons and Indigestibility: Resource Assembly through Joint Ventures," Strategic Management Journal, 21, 195-197.

STOPFORD, J. M., AND L. T. WeLLS JR. [1972], Managing the Multinational Enterprise: Organization of the Firm and Ownership of the Subsidiaries, Basic Books: New York.

TEECE, D. J. [1976], The Multinational Corporation and the Resource Cost of International Technology Transfer, Ballinger: Cambridge, MA.

- - [1977], "Technology Transfer by Multinational Firms: The Resource Cost of Transferring Technological Know-How," Economic Journal, 87, 242-261.

Williamson, O. [1975], Markets and Hierarchies, Free Press: New York.

Zollo, M., AND H. SingH [1998], "The Impact of Knowledge Codification, Experience, Trajectories, and Integration Strategies on the Performance of Corporate Acquisitions," Academy of Management Best Paper Proceedings, The Wharton Financial Institutions Center, Philadelphia, PA.

Cristina López-Duarte

Esteban García-Canal

Dpto. de Administración de Empresas y C.

Fac. de CC. Económicas y Empresariales

Universidad de Oviedo

Avda. del Cristo s/n

33071 Oviedo, Asturias

E-mail:

clopez@econo.uniovi.es

egarcia@econo.uniovi.es 